\title{
NUTRIÇÃO E AUTISMO: REFLEXÕES SOBRE A ALIMENTAÇÃO DO AUTISTA
}

\author{
Vânia Thais Silva Gomes ${ }^{1}$ \\ Raimundo Nonato Silva Gomes ${ }^{2}$ \\ Maria Silva Gomes ${ }^{3}$ \\ Larissa Vanessa Machado Viana ${ }^{4}$ \\ Francileine Rodrigues da Conceição ${ }^{5}$ \\ Laís Mayara Machado de Amorim ${ }^{6}$ \\ Patrícia de Souza Genaro ${ }^{7}$
}

Resumo: O objetivo deste trabalho foi contextualizar uma discussão à cerca da alimentação do autista. Realizou-se uma revisão bibliográfica, nas bases de dados SCIELO, LILACS e PUBMED, sendo incluídos no estudo artigos originais que estivessem sido publicados entre 2004 e 2016 nas línguas inglesa, espanhola ou portuguesa. Relatos de problemas gastrointestinais têm sido frequentemente observados em crianças autistas, além de refluxo, alergias ou intolerâncias alimentares. Isso por que as crianças autistas tendem a apresentar problemas severos de alimentação, devido à seletividade, o que ocasiona em problemas nutricionais, como desnutrição ou obesidade. Conclui-se a dieta isenta de caseína e glúten é considerada uma alternativa segura para amenizar os sintomas gastrointestinais dos autistas, no entanto requer atenção por parte dos nutricionistas, uma vez que é adotada por muitos indivíduos autistas, com resultados satisfatórios.

Palavras-chave: Autismo; Nutrição; Desenvolvimento neuropsicomotor; Dieta.

\footnotetext{
1 Doutoranda em Engenharia Biomédica/Instituto de Pesquisa e Desenvolvimento/UNIVAP, Brasil. E-mail: vaniathais02@hotmail.com.

2 Doutorando em Engenharia Biomédica/Instituto de Pesquisa e Desenvolvimento/UNIVAP, Brasil. E-mail: raigomezz19@hotmail.com.

3 Assistente Social/Faculdade de Ciências e Tecnológica do Maranhão, Brasil. E-mail: assistente.socialmaria23@gmail.com.

4 Mestranda em Engenharia Biomédica/Instituto de Pesquisa e Desenvolvimento/UNIVAP, Brasil. E-mail: laris_machado@hotmail.com.

5 Nutricionista/Faculdade de Ciências e Tecnologia do Maranhão/FACEMA, Brasil. E-mail: wirnamarilia@hotmail.com.

6 Mestranda em Engenharia Biomédica/Instituto de Pesquisa e Desenvolvimento/UNIVAP, Brasil. E-mail: lais_mayara@hotmail.com.

${ }^{7}$ Doutora em Saúde Pública/Universidade do Vale do Paraíba, Brasil. E-mail: psgenaro@gmail.com.
} 